\title{
A degradação ambiental causada pelo descarte inadequado das embalagens plásticas: estudo de caso.
}

\author{
The environmental degradation caused by the inadequate dispose of plastic packs: a case study. \\ Claudionor Oliveira Silva', Gilbertânia Mendonça Santos ², Lucicleide Neves Silva ${ }^{3}$ \\ ' Professor de Geografia. da universidade Estadual de alagoas - UNEAL \\ ${ }^{2}$ Serviço Nacional de Aprendizagem Comercial - SENAC \\ ${ }^{3}$ Faculdade de Formação de Professores da Mata Sul - FAMASUL, professora de biologia.
}

\begin{abstract}
Resumo
A sociedade moderna está acostumada a viver com a facilidade e a versatilidade que as elevadas formas de consumo oferecem. Tendo em vista um alto grau de consumo, a globalização, as inovações tecnológicas que a cada dia buscam garantir seu espaço no mercado, e dessa forma, contribuir para o equilíbrio socioeconômico. A modernização facilitando a vida da população em geral e do outro lado podendo gerar transtornos ambientais é o caso das embalagens plásticas que tem longa duração no ambiente. Com seu desuso e descarte inadequadamente nos ambientes, tornando-os cada vez mais vulneráveis as ações antrópicas, que ocorrem devido aos hábitos culturais e comportamentais de uma grande parcela da população que necessita se reeducar em relação à preservação e conservação do meio ambiente. Esta pesquisa tem como objetivo Informar e sensibilizar os alunos e a comunidade escolar sobre os impactos ambientais, causados pelo descarte inadequado das embalagens plásticas, visando à diminuição de seu consumo e destinação correta no ambiente, através da mudança de atitude e comportamento. Inicialmente foi feito um levantamento bibliográfico sobre resíduos sólidos, formas de disposição do lixo, coleta seletiva e embalagens plásticas. Posteriormente, utilizou-se um questionário auto aplicável para levantamento do conhecimento prévio dos alunos articulados com o referencial teórico. Na sequência houve uma oficina de reciclagem e a implantação da coleta seletiva, acompanhado pelos seguimentos da escola e representantes municipais. Os resultados apontam que muitos alunos desconheciam sobre a coleta seletiva, no entanto com a execução das ações e uso continuo das lixeiras, os resultados foram satisfatórios, pois os educandos aprenderam que é possível preservar o meio ambiente com atitudes simples do cotidiano, através da redução, reutilização, reeducação e reciclagem.
\end{abstract}

Palavras-chaves: : Educação Ambiental; Embalagens plásticas; Coleta Seletiva; Escola Adevan Verçosa e Silva; São Luis do Quitunde.

\begin{abstract}
Modern society is accustomed to living with the ease and versatility that high consumption forms offer. Given a high level of consumption, globalization, technological innovations that seek every day to ensure your space in the market, and thereby contribute to the socioeconomic balance. The modernization making life easier for the general public and the other side may generate environmental disorders is the case of plastic packaging has on the environment long term. With their disuse and dispose inappropriately environments, making them increasingly vulnerable human actions that occur due to cultural and behavioral habits of a large portion of the population that needs to reeducate themselves regarding the preservation and conservation of the environment. This research aims to inform and sensitize students and the school community about the environmental impacts caused by the improper disposal of plastic packaging in order to reduce their consumption and proper disposal in the environment by changing attitudes and behavior. Initially a literature review was done on solid waste, forms of waste disposal, waste sorting and plastic packaging. Later, it was used to apply a self lifting students' prior knowledge articulated with the theoretical. As a result there was a recycling workshop and implementation of selective collection, accompanied by segments of the school and municipal representatives. The results show that many students did not know about the selective collection, however with the implementation of actions and continuous use of bins, the results were satisfactory, since the students have learned that it is possible to preserve the environment with simple everyday by reducing, reuse, re-education and recycling.
\end{abstract}

Keywords: Environmental Education; Plastic Packaging; Selective Collection; School Adevan Verçosa e Silva, Sao Luis do Quitunde. 


\section{INTRODUÇÃOO}

Antes da primeira Revolução Industrial o lixo produzido nas residências era composto basicamente de matéria orgânica, dessa forma era fácil eliminá-los, bastava enterrar, além disso, as cidades eram menores e o número da população restrita (SANTOS, 2010, p.7).

O modelo de desenvolvimento em que vivemos, vem causando alterações constantes ao meio ambiente. Tais alterações estão relacionadas principalmente ao aumento da população, incentivo e elevação do consumo, globalização e inovações tecnológicas. Essas inovações tecnológicas surgiram a partir da primeira Revolução Industrial no século XVIII e sua dispersão mundial desencadeou significativamente grandes impactos negativos ao meio ambiente, por meio das ações antrópicas. Dentre eles destacam-se a disposição inadequada dos resíduos sólidos, principalmente os feitos de plástico.

Não é sem razão que já se convencionou chamar o nosso tempo de Era do Plástico. O plástico evoluiu da posição de sucedâneo à de matéria prima essencial para um cem números de especificações, e a cada nova necessidade da vida moderna logo emerge das provetas um material sintético mais racional, mais abundante, mais uniforme, mais econômico (RAMALHO, 2009, p.13).

Em função da sua pouca degradabilidade os plásticos permanecem na natureza por períodos longos, causando a poluição visual e, eventualmente, química do ambiente, para reduzir o impacto dos plásticos no ambiente o gerenciamento dos resíduos torna-se imperativo e, desta forma a estratégia da reciclagem pode ser facilmente introduzida. (XAVIER et al., 2006, p.3)

Quando o lixo é disposto de forma inadequada, em lixões em céu aberto, por exemplo, são inevitáveis problemas sanitários e ambientais. Isso porque estes locais tornam-se propícios para a atração de animais que acabam por se constituírem em vetores de diversas doenças, especialmente para as populações que vivem da catação, uma prática comum nestes locais. Além do mais, são responsáveis pela poluição do ar, quando ocorre a queima dos resíduos, no solo, e das águas, dos lençóis freáticos e superficiais (RIBEIRO; ROOKE, 2010, p.11). O não tratamento, ou o tratamento inadequado dos grandes volumes de lixo contribuirá para a degradação da biosfera em relação à qualidade de vida no nosso planeta. (OLIVEIRA, et al., 2012, p.90). Observando-se a destinação $\square$ nal dos resíduos, os vazadouros a céu aberto (lixões) constituem em 50,8\% dos municípios brasileiros, conforme revelou a Pesquisa Nacional de Saneamento Básico 2008.

A poluição ambiental é um dos grandes desafios da humanidade, mas ela pode e deve ser enfrentada por meio de práticas educativas que priorize a educação ambiental, mas para que isto aconteça é fundamental a formação dos profissionais da educação, para que eles saibam como planejar/executar ações de forma que as mesmas contemplem os princípios da educação ambiental e atenda a realidade local.

Dentre as ações que visam proteger o meio ambiente está a Coleta Seletiva aliada à educação ambiental como ferramenta para mitigar os efeitos dos descartes inadequados dos resíduos. Uma das ações corretivas é a reciclagem, mas para reciclar, é necessário separar os materiais a partir da coleta seletiva que é um sistema de recolhimento de materiais recicláveis. (PIMENTEL et al., 2011).

A Educação Ambiental deve estar voltada para o desenvolvimento sustentável, a integração entre desenvolvimento e ambiente é o principio básico e diretor da educação e da educação ambiental. Com essa preocupação a proposta é reorientar o ensino formal e informal, modificando atitudes e comportamentos pela aquisição de conhecimento e valores. Entende-se que a universalização à educação básica é uma estratégia de promoção da equidade e compensação das disparidades econômicas, sociais e gênero (TOZONI-REIS, 2004, p. 6). A principal função do trabalho com o tema Meio Ambiente é contribuir para a formação de cidadãos conscientes, aptos para decidirem e atuarem na realidade socioambiental de um modo comprometido com a vida, com o bem estar de cada um e da sociedade, local e global (PCN, 1997, p.29).

A abordagem desta pesquisa refere-se principalmente ao descarte inadequado das embalagens plásticas em fragmentos do ambiente urbano, ocasionados pelas formas de uso, costumes e hábitos culturais, acarretando dessa forma poluição ambiental. A problemática ambiental gerada pelo descarte indevido das embalagens plásticas pode ser minimizada através de ações sustentáveis como a coleta seletiva aliada a educação ambiental, promovendo assim o equilíbrio do meio ambiente.

\section{METODOLOGIA}

\section{I Área de estudo}

O estudo foi desenvolvido no município de São Luiz do Quitunde - AL, Região Nordeste do 
Brasil. Apresenta clima tropical litorâneo úmido e índice pluviométrico de $79,2 \%$. Sua vegetação predominante é Mata Atlântica, com clima temperado. O estudo de caso ocorreu na Escola Municipal Adevan Verçosa e Silva, estando situada na Rua Eraldo Pedro da Silva, S/N na área urbana do município. A escola atende alunos do ensino fundamental II, num total de 1112 . O quadro de funcionários é composto por 110 pessoas. Em relação ao espaço físico, a escola apresenta 10 salas de aulas, 1 diretoria, 1 sala de coordenação, 1 cozinha, 2 banheiro, 1 biblioteca, 1 secretaria e 1 laboratório de informática. Figura 1.

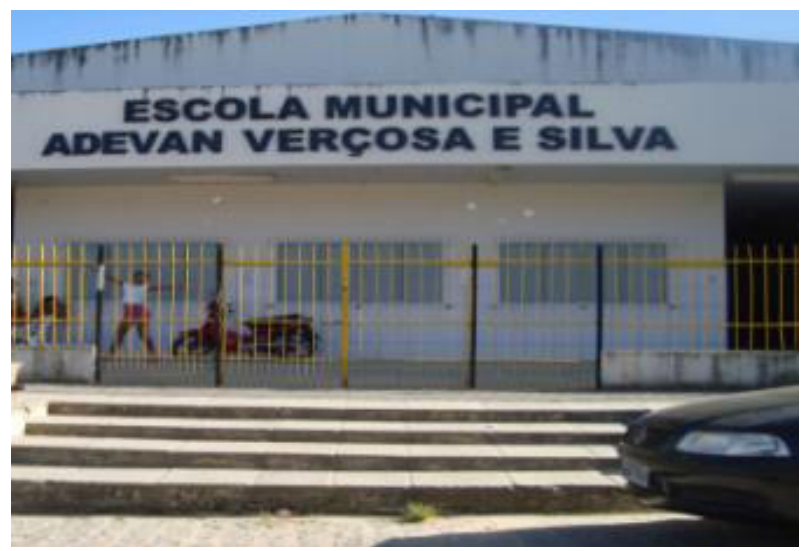

Figura 1 - Escola Adevan Verçosa e Silva

2.2. Levantamento dos dados

Inicialmente foi feito um levantamento bibliográfico sobre resíduos sólidos, formas de disposição do lixo, coleta seletiva e embalagens plásticas. Posteriormente, utilizou-se um questionário auto aplicável com 12 perguntas, para levantamento do conhecimento prévio dos alunos articulados com o referencial teórico.

Serviram como amostra 280 alunos, entre 10 e 18 anos, do $6^{\circ}$ ao $9^{\circ}$ ano do ensino fundamental II.

Na sequência houve a implantação da coleta seletiva e uma oficina de reciclagem.

Houve a participação nas ações do projeto à prefeitura municipal, departamento de meio ambiente, secretaria de educação e usina Santo Antonio. Foram realizadas reuniões com o gestor escolar, professores, auxiliares de serviços gerais e cozinheiras, a fim de mostrar os objetivos da pesquisa e algumas ações a serem executadas.

\section{RESULTADO E DISCUSSÃO}

Os resultados serão apresentados conforme sequência do roteiro da aplicação do questionário auto aplicável composta por 12 perguntas. Em sequência a Implantação da coleta seletiva, criação e festival de paródias, criação e exposição de cartazes, palestra com gestores da escola e representantes municipais, oficina de reciclagem.

O questionário serviu para o levantamento do conhecimento prévio dos alunos. As questões referiam-se em linhas gerais sobre os resíduos sólidos, coleta seletiva, reciclagem, resíduos plásticos e sua durabilidade no ambiente, bem como o consumismo e a preservação ambiental.

Com base nos resultados, foi possível constatar que $81.07 \%$ dos entrevistados tinham conhecimento de que nem tudo que é jogado fora é lixo. Esse fato pode ter ocorrido devido os alunos já terem em algum momento praticado a reutilização das embalagens plásticas no seu cotidiano, ou terem observado outras pessoas reaproveitando tais materiais, citado como exemplo o caso dos catadores de resíduos sólidos. Entretanto, os $18.93 \%$ entrevistados disseram que tudo que é jogado fora é lixo, talvez por não terem percebido ações desse tipo em sua casa ou outros locais que frequentavam. Não foi questionado aos discentes se eles reutilizavam materiais plásticos, perguntamos apenas se tudo que é jogado é lixo ou não.

Quando questionados sobre o que mais seus familiares jogam no lixo 236 (84.28\%) afirmaram que a maioria dos resíduos sólidos são plásticos e papel, e apenas 44(15.71\%) afirmaram que o vidro e o metal são os mais descartados. Conforme tabela 1.

Tabela 1 - Resíduos sólidos mais descartados pelos familiares.

\begin{tabular}{|c|c|}
\hline $\begin{array}{c}\text { Tipos de } \\
\text { resíduos sólidos }\end{array}$ & $\mathbf{\%}$ \\
\hline Plástico e Papel & 84.28 \\
Vidro e Metal & 15.71 \\
\hline
\end{tabular}

No que diz respeito à coleta seletiva 153 (54.64\%) dos entrevistados desconheciam o assunto e 118 (42.14\%) já sabiam do que se referi, apenas 9 alunos (3.21\%) não opinaram. Acredita-se que os alunos em geral, sabem o significado e a importância da coleta seletiva para o meio ambiente, e segundo depoimentos de alguns funcionários, as embalagens plásticas eram jogadas na maioria das vezes em vários locais da escola.

Quanto a questão da coleta de lixo, 169 $(60.35 \%)$ dos escolares entrevistados tinha coleta de lixo diariamente na rua em que moravam, e $106(37.85 \%)$ que não havia a coleta frequente- 
mente, e apenas 2 não opinou. $O$ índice elevado de alunos que afirmaram não ter coleta de lixo em sua rua pode representar a quantidade de alunos que residem na área rural, a qual sofre com o não gerenciamento dos diversos resíduos, descartando-os inadequadamente em vales, rios, quintais, terrenos baldios, entre outros. Tornando-se um agravante ambiental. Apenas $1.78 \%$ dos alunos não responderam o enunciado citado acima.

$\mathrm{Na}$ questão referente à reciclagem e a preservação da natureza, 248 (88.57\%) dos escolares concordaram que separando os resíduos sólidos estariam contribuindo para a preservação do meio, entretanto $32(11.42 \%)$ responderam que não. Ao serem questionados sobre a matéria prima do plástico convencional $166(59.28 \%)$ afirmaram ser do petróleo, 76 (27.14\%) disseram ser de árvores, $29(10.35 \%)$ disseram ser feito de cana-de-açúcar e $9(3.21 \%)$ não opinaram. Conforme tabela 2.

Tabela 2 - conhecimento dos alunos sobre a matéria prima do plástico.

\begin{tabular}{|c|c|}
\hline $\begin{array}{c}\text { Tipos de } \\
\text { matérias- prima }\end{array}$ & $\mathbf{\%}$ \\
\hline Árvores & 27.14 \\
Petróleo & 59.28 \\
Cana-de-açúcar & 10.35 \\
\hline
\end{tabular}

Em relação à durabilidade do plástico no meio ambiente, constatou-se que, 213 dos escolares (76.07\%) afirmaram não ter ideia do tempo de decomposição desse material, 63 (22.5\%) deles afirmaram saber do tempo de decomposição e apenas $4(1.44 \%)$ não responderam. A durabilidade das embalagens plásticas no meio ambiente tornou-se um dos mais graves problemas ambientais, devido à cultura que se dá a destinação inadequada a tais materiais.

O consumismo também é um dos grandes vilões que vem causando danos ao meio ambiente, pois sabe-se que quanto mais se consome mais se descarta materiais de forma inadequada, principalmente o plástico. Com o resultado da pesquisa foi possível perceber que a maioria dos escolares $182(65.35 \%)$ responderam comprar apenas o necessário, evitando assim o abuso de consumo. No entanto, 97 responderam que compram além do que necessitam.

De acordo com o levantamento de dados sobre a implantação da coleta seletiva na escola, foi diagnosticado que, 226 (80.71\%) dos entrevistados afirmaram que usariam as lixeiras para separar os resíduos sólidos, 51(18.21\%) disseram que só separariam os resíduos sólidos nas lixeiras especificas quando lembra-se e apenas $3(1,07 \%)$ disseram que não utilizariam as lixeiras.

A implantação da coleta seletiva foi uma ação pioneira no município, realizada na escola municipal Adevan Verçosa e Silva, por esse motivo surgiram algumas dificuldades que poderiam estar relacionadas com os fatores socioculturais dos envolvidos no projeto. Contudo, a adesão à pesquisa foi totalmente satisfatória, onde todos passaram a utilizar de forma correta e espontânea as lixeiras. Isso mostra a importância do trabalho efetivo de educação ambiental no ambiente escolar, para que haja mudanças de atitudes e comportamento do ser humano.

Na sequência, houve uma palestra que reuniu os parceiros do projeto, entre eles o Departamento de Meio Ambiente, Usina Santo Antonio, profissionais da educação como a Secretária Municipal de Educação, gestores da escola campo da pesquisa e de escolas convidadas, professores e alunos, onde o objetivo era expor a importância da educação ambiental para a minimização do descarte inadequado dos resíduos plásticos no meio ambiente.

A Educação Ambiental se concretiza pela adoção de uma abordagem metodológica interdisciplinar, da complexidade, do conhecimento baseado em valores e práticas sustentáveis, indispensáveis para estimular o interesse e o engajamento de cidadãos e cidadãs na ação e na responsabilidade. (JACOBI et al, 2009, p.65 - 66). Sendo assim, percebe-se a necessidade de adoções de práticas concretas e efetivas nas escolas e demais locais, visando um ambiente equilibrado e sustentável.

$\mathrm{Na}$ oportunidade do evento, ocorreu a implantação da coleta seletiva, sendo disponibilizados quatro conjuntos de lixeiras para coleta seletiva, com cinco unidades cada conjunto. As quais foram confeccionadas com material plástico reutilizável. Conforme figura 2 .

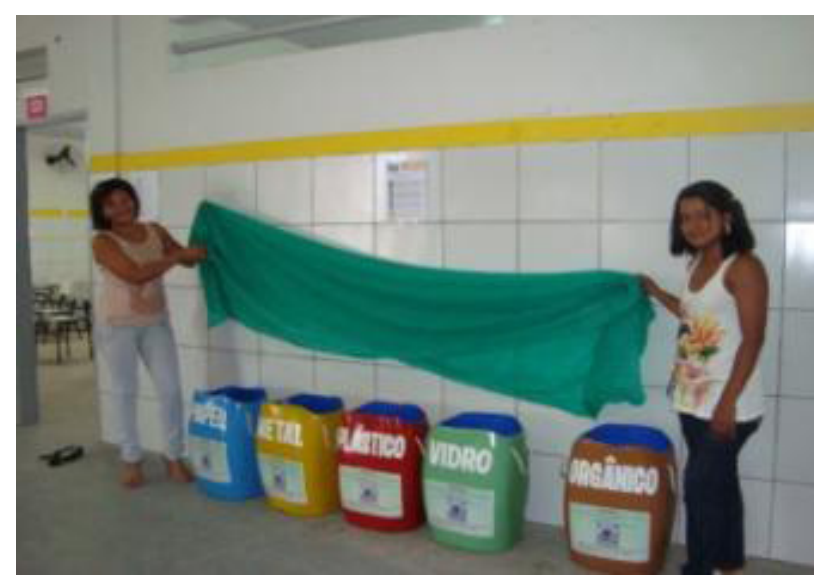

Figura 2 - Entrega das lixeiras ecológicas 
Diante dos altos níveis de degradabilidade ambiental, os órgãos públicos e privados e a população em geral devem adotar uma postura consciente, buscando amenizar os impactos negativos ao meio ambiente causados pelo descarte inadequado dos resíduos sólidos. Dentre as ações que visam proteger o nosso planeta, encontra-se a coleta seletiva, uma prática simples de recolhimento de materiais, mas que tem um alto valor ecológico, social e educacional.

Segundo PIMENTEL (2011), Os resíduos sólidos geralmente descartados em aterros sanitários ou lixões, assim representando um enorme desperdício de energia e matéria-prima, resultando em problemas ambientais que aumenta com a ausência de gestão ambiental. Sendo assim, a adoção de práticas sustentáveis transforma-se em instrumento necessário para um meio ambiente equilibrado.

Para consolidar o conhecimento adquirido pelos discentes sobre o tema: Degradação Ambiental Causada pelo Descarte inadequado das Embalagens Plásticas foram realizadas atividades tais como, pesquisa de campo que auxiliou na produção de vídeos, slides e debates. Houve também a criação e festival de paródias. Conforme figura 3.

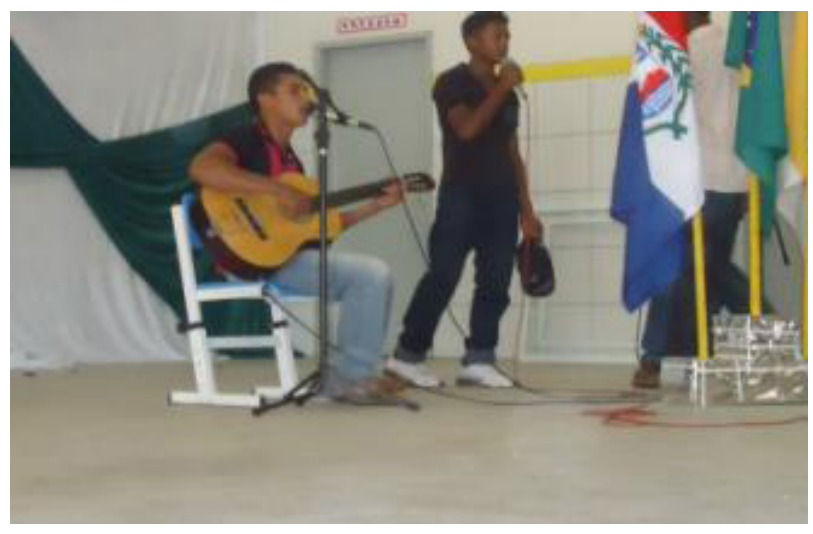

Figura 3 - Festival de paródia

As oficinas de reciclagem aconteceram, onde os discentes tiveram a liberdade de expor suas habilidades artísticas, confeccionando objetos com materiais plásticos reutilizáveis como, garrafa pet, potes de alimentos, produtos de limpeza, entre outros. Na oportunidade aprenderam que é possível preservar o meio ambiente com atitudes simples do cotidiano, através da redução, reutilização e reciclagem. Conforme figura 4 e 5 .

Diante da complexidade que o descarte inadequado das embalagens plásticas apresenta no ambiente, torna-se necessário uma visão sistêmica e integrada a Educação Ambiental sendo possível minimizar os impactos causados pelos resíduos

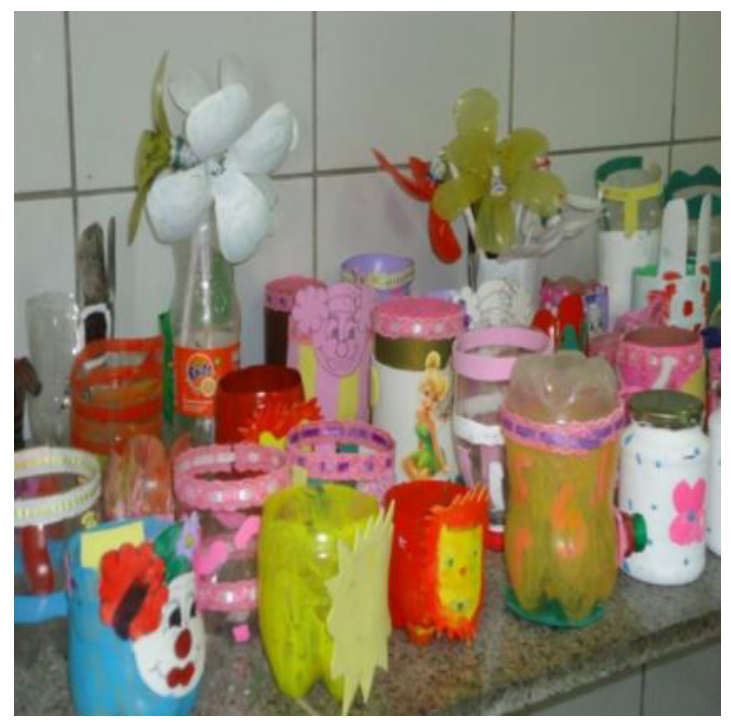

Figura 4 - Oficina de reciclagem

sólidos a base de plásticos, através de mudanças de hábitos e comportamentos no dia a dia.

Em relação aos tipos de materiais mais descartados por seus familiares, quase todos os escolares disseram ser o plástico e o papel. Esse resultado pode ter ocorrido devido a grande quantidade de produtos industrializados e embalados com esses materiais. Os demais alunos responderam ser o vidro e o metal. Esses dados podem ser justificados pelo fato dos produtos mais consumidos pelos familiares, não estarem embalados nas embalagens citadas a cima.

Sobre a coleta seletiva, mais da metade dos alunos, desconheciam o assunto. Os alunos em geral sabem o significado e a importância da coleta seletiva para o meio ambiente, e segundo depoimentos de alguns funcionários, as embalagens plásticas e outras eram lançadas na maioria das

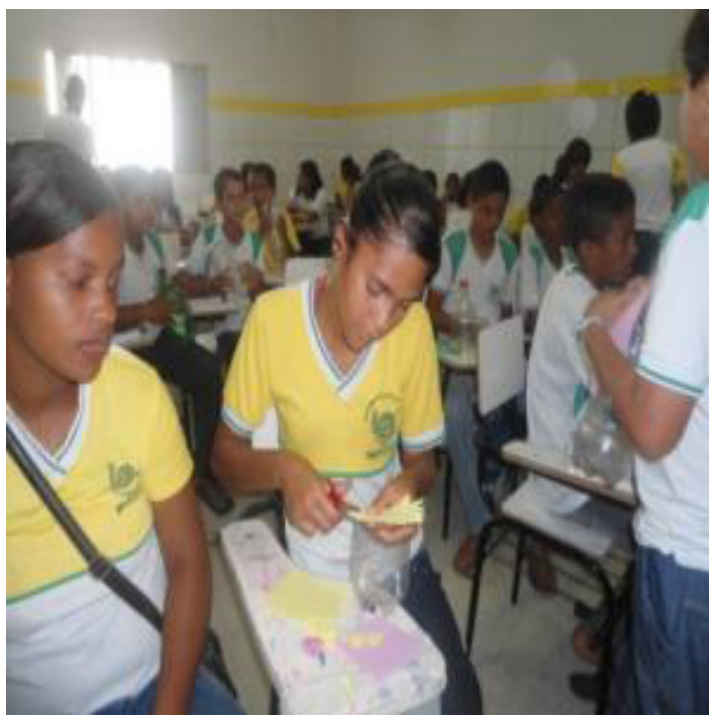

Figura 5 - Objetos confeccionados 
vezes em várias partes da escola.

A implantação da coleta seletiva foi uma ação pioneira no município de São Luís do Quitunde - AL, realizada na escola municipal Adevan Verçosa e Silva, e talvez por esse motivo surgiram algumas dificuldades, destacando-se a falta de apoio dos funcionários, que pode está relacionada com os fatores socioculturais desses indivíduos, ocasionando pouco interesse pelo projeto, e mesmo afirmando que o descarte inadequado dos resíduos sólidos diminuíram significantemente no pátio escolar, facilitando o trabalho de limpeza, porém esses mesmos funcionários dificilmente separavam os resíduos recolhidos por eles nas lixeiras adequadas, além disso utilizavam as mesmas para outros fins.

Quanto à destinação das embalagens recolhidas na escola, não ocorreu da forma programada, devido a não reciclagem de materiais como as embalagens de pipocas, balas, entre outras, plásticos que não são reciclados, segundo o catador de resíduos sólidos cadastrado pelo projeto, já que no município não há cooperativa, este fato causou certo desequilíbrio no andamento do projeto, uma vez que estas embalagens são as mais geradas no ambiente escolar. Restando apenas as embalagens de produtos de limpeza, de alimentos da merenda, pet, entre outros.

Referente à coleta do lixo no município, mais da metade dos entrevistados responderam que em sua rua havia coleta diariamente, os demais responderam que não, isso pode representar a quantidade de alunos que residem na área rural, a qual sofre com o não gerenciamento dos diversos resíduos, descartando-os inadequadamente em vales, rios, quintais, terrenos baldios, entre outros, tornando-se um agravante ambiental.

No questionamento em relação à importância da reciclagem para o meio ambiente, quase todos os alunos afirmaram que separando os resíduos sólidos, estariam preservando o meio ambiente e a minoria dos escolares responderam que esta ação não ajudaria na preservação ambiental. Acredita-se que o índice elevado dos alunos sobre o conhecimento da importância de reutilizar e reciclar diversas embalagens, pode ter ocorrido devido informações formais e informais, pois acredita-se, que se cada um fizer sua parte $o$ ambiente só tem a ganhar, sabendo dos benefícios dessa ação é que a maioria dos alunos participam com prazer da coleta seletiva na escola.

Quando questionados sobre a matéria prima do plástico um pouco mais da metade afirmaram ser do petróleo, os demais disseram ser de árvores e de cana de açúcar. $\mathrm{O}$ alto índice de escolares que conhecem a base do plástico convencional não torna-se uma novidade, pois o mesmo é o mais divulgado pelas mídias, Já os bioplásticos ainda não são tão utilizados ou produzidos em larga escala, diminuindo dessa forma o conhecimento sobre o mesmo.

A durabilidade das embalagens plásticas no meio ambiente torna-se um dos mais graves problemas ambientais, devido a cultura de uma destinação inadequada a tais materiais, e em relação a este tema a maioria dos entrevistados afirmaram não saber o tempo de duração desses materiais no ambiente, e poucos sabiam de sua durabilidade e a maioria dos escolares não sabiam o tempo de decomposição dos materiais plásticos no meio ambiente, no entanto é possível que com o desenvolvimento da pesquisa e suas ações tenham obtido mais conhecimentos a este respeito.

O consumismo também é um dos grandes vilões que vem causando danos ao meio ambiente, pois sabe-se que quanto mais se consome mais se descarta materiais de forma inadequada, principalmente o plástico. Em relação ao consumismo a maioria dos entrevistados afirmaram comprar apenas o necessário os demais disseram comprar além do que é preciso.

Ao serem entrevistados, sobre a coleta seletiva e como eles agiriam se em sua escola tivesse as lixeiras para a separação dos resíduos sólidos, principalmente os feitos de plásticos a maioria dos discentes responderam que separariam os resíduos, enquanto que, poucos afirmaram que só usariam as lixeiras para separar os resíduos, quando lembrassem.

Para o encerramento das ações previstas no projeto, ocorreram apresentações dos alunos no pátio escolar, onde os mesmos puderam expor seu conhecimento sobre o tema Embalagens Plástica e Degradação Ambiental, através de vídeos, slides, festival de paródias e embolada, produzidos pelos alunos. Além de oficina de reciclagem onde os alunos mostraram sua criatividade reutilizando diversas embalagens plásticas. O êxito das ações desenvolvidas neste projeto de pesquisa, contou com a colaboração dos educadores de Arte, língua portuguesa, Educação física e Ciência naturais. Devido o curto tempo para a realização da pesquisa não foi possível envolver as demais disciplinas. Mesmo assim, podemos afirmar que houve uma visível mudança de hábitos e comportamento da maioria dos escolares, diminuindo assim o descarte inadequado no ambiente escolar e possivelmente em outros ambientes. 


\section{CONSIDERAÇÕES FINAIS}

Um dos grandes desafios da população atual é destinar adequadamente os resíduos sólidos, principalmente os feitos à base de plástico, uma vez que os mesmos apresentam durabilidade no ambiente devido aos seus componentes químicos. Mesmos os que são considerados biodegradáveis, não ajudam a resolver os problemas gerados pelos descartes indevidos desses materiais, ao contrario do que se imaginava, por não sofrerem ações dos microrganismos, simplesmente fragmentam-se em partes menores, diminuindo apenas o volume dessas embalagens no ambiente.

Dessa forma, percebe-se a necessidade de promover ações efetivas de educação ambiental que desenvolvam um comportamento consciente e responsável nos escolares, em toda comunidade escolar, familiares e consequentemente em toda sociedade, através de ações individuais e coletivas, com o propósito de reduzir o consumo desnecessário de embalagens plásticas, bem como sua reutilização e possivelmente uma destinação adequada. A coleta seletiva e a reciclagem tornam-se aliadas para a mitigação dessa problemática que causa desequilíbrio ambiental. Sendo assim, a humanidade precisa priorizar as atitudes sustentáveis para que possam usufruir o bem estar social e ambiental.

Diante de observações, estudos e práticas, foi possível diagnosticar nessa pesquisa que mais da metade dos alunos não tinham conhecimento da importância sobre a coleta seletiva e menos ainda sobre os danos provocados pelo descarte inadequado das embalagens plásticas, entre outros resíduos sólidos. No entanto, obtivemos nessa pesquisa um resultado satisfatório, onde os alunos demonstraram com prática a relevância do descarte adequado dos materiais foco da pesquisa.

Sabe-se que elaborar um projeto de educação ambiental não é tarefa fácil, pois exige um comprometimento efetivo de todos os envolvidos na pesquisa, como também o tempo reduzido para a excussão das ações programáticas. Mesmo assim, espera-se que a escola campo da pesquisa dê continuidade com a coleta seletiva e demais ações que colaborem com a sustentabilidade urbana.

Durante a execução das ações houveram dificuldades, destacando-se a falta de zelo e desvio das lixeiras para outras finalidades, isso por parte dos funcionários da escola e o recolhimento dos resíduos sólidos não aconteceu conforme o planejado, provocando assim, desequilíbrio à pesquisa.

\section{REFERENCIAS BIBLIOGRÁFICAS}

\author{
JACOBI, P. R.; TRISTÃO, Martha; FRANCO,
}

Maria Isabel Gonçalves Correa. A função social da educação ambiental nas praticas colaborativas: participação e engajamento. CAD. SEDES, Campinas, vol. 29, n. 77, p.63-79, jan./abr. 2009. Disponível em < HTTP:// www.Cedes.unicamp.br > acesso em: 15 nov. 2012.

OLIVEIRA, L. L. et al. Impactos ambientais causados pelas sacolas plásticas: o caso Campina grande - PB. Biofar, 2012.

PIMENTEL, A. K. S.; ARAUJO, K. K. S.; ROCHA , M. V. R. Coleta seletiva em uma empresa de limpeza publica de Maceió (AL). Maceió 2011.

PCN- Parâmetros curriculares nacionais: meio ambiente e saúde/ Secretaria de Educação Fundamental. - Brasília: 1997, 128p.

RAMALHO, M. Plásticos Biodegradáveis Provenientes da Cana de Açúcar. São Paulo, Faculdade de Tecnologia da zona Leste, 2009.

RIBEIRO, J. W.; ROOKE, J. M. S. Saneamento básico e sua relação com o meio ambiente e a saúde publica. Juiz de Fora, MG. 2010.

SANTOS, H. M. M. Disposição final dos resíduos sólidos em Maringá-PR: Impactos e soluções. Dezembro 2010.

TOZONI - REIS, M. F. C. Educação Ambiental: natureza, razão e história. Campinas, SP: Autores Associados. 2004. (Coleção educação contemporânea).

XAVIER, L. H. et al. Legislação ambiental sobre destinação de resíduos sólidos: o caso das embalagens plásticas pós-consumo. XIII SIMPEP - Bauru, SP, Brasil, 6 a 8 de novembro de 2006. 